\title{
Análise de injecção em fluxo (FIA)
}

M. FILOMENA G.F.C. CAMÕES*

\begin{abstract}
A Análise de Injecção em Fluxo (FIA) consiste na injecção repetida de um pequeno volume de amostra num líquido transportador que, em condições hidrodinamicamente controladas, se desloca de forma contínua e não segmentada até um detector que acusará um sinal tendencialmente gaussiano. Durante 0 percurso, outros líquidos transportadores, reactivos ou não, podem eventualmente juntar-se ao primeiro, podendo a amostra ser submetida a toda uma gama de processos físico-químicos.

As operações postas em prática reflectem-se na maior ou menor dispersão da amostra no(s) líquido(s) transportador(es). 0 valor do coeficiente de dispersão definido em relação ao estado estacionário, depende das características da montagem experimental e constitui um critério de classificação para a técnica a ter em conta para as diferentes aplicações.

A técnica de FIA, pela sua simplicidade, elegância, rapidez, economia de reagentes, possibilidade de automatização e maior conteúdo de informação, encontrou rápido desenvolvimento e vasta aplicação laboratorial.
\end{abstract}

\section{PRINCíPIOS DA ANÁLISE DE INJECÇÃO EM FLUXO}

A expressão «Análise de Injecção em Fluxo (FIA)" foi usada a primeira vez em 1975 por Ruzicka e Hansen [1] para designar a operação que consistia em injectar uma solução/amostra num fluido em movimento que a conduzia a um detector, espectrofotométrico no caso de uma solução de fosfatos, ou potenciométrico no caso de uma solução amoniacal. metodologia foi no entanto da autoria de Nagy et al. [2] que introduziram uma câmara de mistura no percurso da amostra, permitindo homegeneização rápida e completa da amostra injectada com o fluido transportador.

A análise por injecção em fluxo consiste, na sua versão mais simples, na injecção repetida de um pequeno volu$\mathrm{me}, \mathrm{V} / \mu \mathrm{l}$, de uma solução de amostra num fluido em movimento; este líquido transportador, que se desloca de forma contínua, $\mathrm{Q} / \mathrm{ml} \mathrm{min}^{-1}$, não é segmentado e as zonas formadas pelas injecções repetidas são assim transportadas, em condições hidrodinamicamente controladas, até um detector que assinalará as variações de um parâmetro físico-químico característico de amostra, ou de algum dos seus constituintes.

A análise em fluxo contínuo distingue-se da análise em fluxo segmentado, característico dos Auto-analisadores Technicon, pelo facto de, nesta, as amostras serem separadas por bolhas de ar e conservarem a sua identidade. Se nesta última as amostras são envolvidas em reacções químicas, tenta-se geralmente atingir equilibrio químico antes da passagem pelo detector, 0 que nem sempre acontece em FIA. A análise em fluxo contínuo distingue-se também da cromatografia líquida, outra técnica de fluxo, pois nesta há a separação dos constituintes da mistura a analisar.

Durante 0 seu percurso, a amostra pode ser submetida a toda uma gama de processos físicos, químicos ou físicoquímicos (ex.: diluição, reacções químicas, passagem através de membranas de diálise, extracção líquido-líquido). Outros líquidos transportadores, reactivos ou não, podem eventualmente juntar-se ao primeiro em diferentes pontos compreendidos entre a injecção e o detector; os vários líquidos deslocam-se em tubos de pequeno diâmetro interior, $d / 0.1 \mathrm{~mm}$, formando no seu conjunto o que se pode

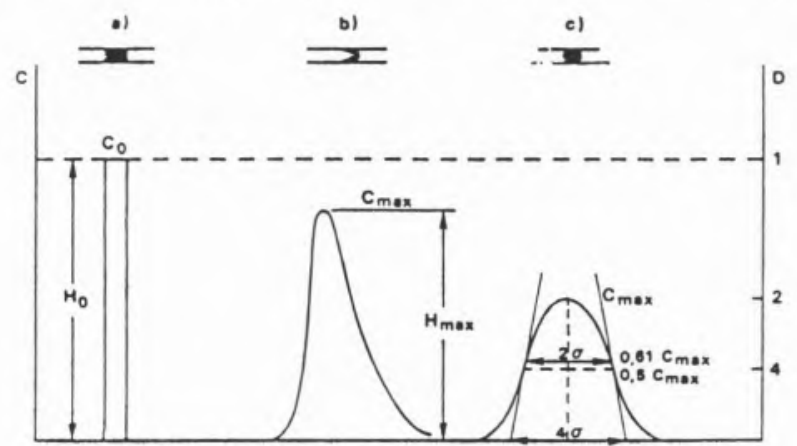

Figura 2 - Representação esquemática do sinal obtido em FIA: a) injecção

(a)

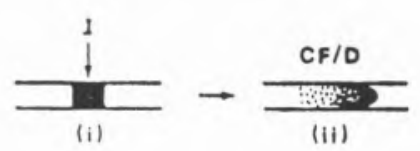

(b) dispersão da amostra (b)

I: injecção L: comprimento do manifold

$P$ : bomba $\quad Y$ : registador

E: saída

designar por um micro-reactor tador(es) [3]

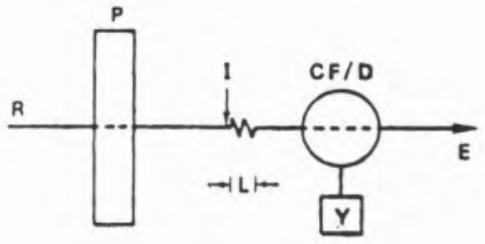

Figura 1 - Esquema de montagem simples de FIA (a) e representação do fenómeno de

$\mathrm{R}$ : reagente CF/D: detector de fluxo contínuo

Todas as operações postas em prática se reflectem numa dispersãodiluição da amostra no(s) líquido(s) transportador(es) e têm como objectivo último proporcionar as condições que permitam a posterior detecção especifica de um dos constituintes da amostra, ou de um seu derivado, quando a zona correspondente atravessar 0 detector onde é conduzida pelo(s) líquido(s) transpor-

Na Figura 1 encontra-se a representação esquemática da montagem laboratorial mais simples que permite $\begin{array}{ll} & \text { b) perfil de dispersão assimétrica } \\ \text { c) perfil de dispersão gaussiana }\end{array}$

$\begin{array}{ll} & \text { b) perfil de dispersão assimétrica } \\ \text { c) perfil de dispersão gaussiana }\end{array}$ 
pôr o princípio em prática, (a), bem como a evolução do perfil de concentração da amostra desde a injecção até ao detector, (b).

A passagem no detector da zona que corresponde à injecção de amostra produz um sinal cuja evolução tem as características genéricas indicadas na Figura 2. Em oposição às características de estado estacionário, obtém-se um pico assimétrico de pendor inicial elevado, seguido de um ramo de decrescimento exponencial; naturalmente um maior percurso da zona resultará no seu alargamento tornando-se o pico mais largo e eventualmente gaussiano.

Ainda que de desenvolvimento recente a FIA encontra já vasta aplicação laboratorial [4]. A técnica impôs-se pela sua simplicidade, elegância, rapidez, economia de reagentes e possibilidades de automatização, diminuindo as operações manuais, o que conduz a maior informação analítica.

Tendo em conta o rápido desenvolvimento da FIA é também possivel e até desejável, classificar as aplicações analiticas com base no processo reaccional que ocorre durante 0 transporte da amostra. Um critério seguido é o esquematizado na Tabela 1.

\section{Tabela 1. Diferentes Processos Reaccionais Associados a Análise de Injecção em Fluxo}

Reacçōes Químicas $(1,3,4,5,6,15,17)$ Reacçōes e Métodos Enzimáticos $(8,9,10)$ Métodos Separativos (extracção, diálise, tro ca-iónica, difusão gasosa) $(6,11,12,13,14)$

\section{PARÂMETROS DA DILUIÇÃO-DISPERSÃO DA AMOSTRA EM FIA}

\section{Factor de dispersão}

Para caracterizar os aspectos experimentais da técnica, faz-se alusão a termos como sejam o tempo de permanência ou de residência e o factor de diluição, que facilitam a definição das condições de operação de um sistema de FIA e a comparação de resultados experimentais.

0 tempo $t$ que medeia entre a injecção e o máximo do pico, designa-se por tempo de permanência ou de residência.

0 factor ou coeficiente de diluição ou de dispersão $D$ reflecte os fenómenos de transporte, diluição e dispersão que afectam a amostra no liquido transportador desde a sua injecção até ao detector e define-se pela relação

$$
D=C_{0} / C_{\max }
$$

$-C_{0}=$ concentração inicial na amostra injectada, da espécie química analisada

$-C_{\max }=$ concentração da espécie no máximo do pico

Em primeira aproximação este coeficiente pode ser determinando, para uma dada montagem experimental, de forma simples, injectando uma solução corada num liquido transportador quimicamente inerte e medindo de forma contínua a absorvância. Admitindo que se observa a lei de Lambert-Beer, a altura do pico $\left(\mathrm{H}_{\max }\right)$, correcção feita para a linha de base, é directamente proporcional à concentração da substância corada; outra determinação de absorvância da amostra corada inicial, não diluída, em condições estacionárias, permite obter $\mathrm{H}_{0}$. $\mathrm{O}$ coeficiente de diluição ou dispersão, grandeza adimensional, é então igual à razão destas duas medidas.

$$
D=H_{0} / H_{\max }
$$

À diluição-dispersão da amostra no líquido transportador corresponde também uma diluição-dispersão deste naquela, como se evidencia na Figura 3.
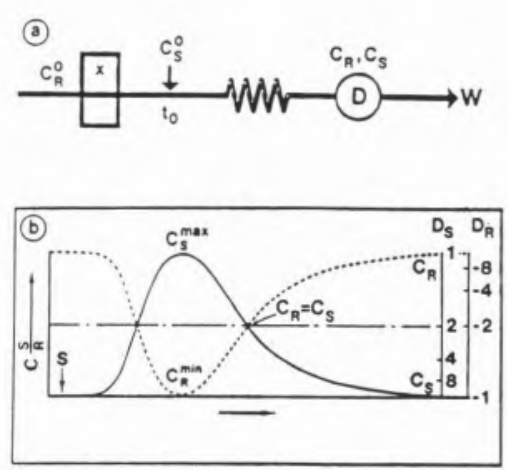

Figura 3 - Perfis de dispersão mútua (b) de amostra (s) e de reagente (R) numa linha de FIA (a)
Pode definir-se neste caso um factor de diluição $D_{R}$ que se pode relacionar [15] com 0 factor $D_{S}$ definido para a amostra injectada da seguinte forma:

$$
\frac{1}{D_{S}}+\frac{1}{D_{R}}=1
$$

Caso haja várias linhas de fluidos transportadores a expressão alarga-se a todos eles

$$
\frac{1}{D_{S}}+\frac{1}{D_{R_{1}}}+\frac{1}{D_{R_{2}}} \quad \cdots=1
$$

\section{Altura de pico e volume injectado}

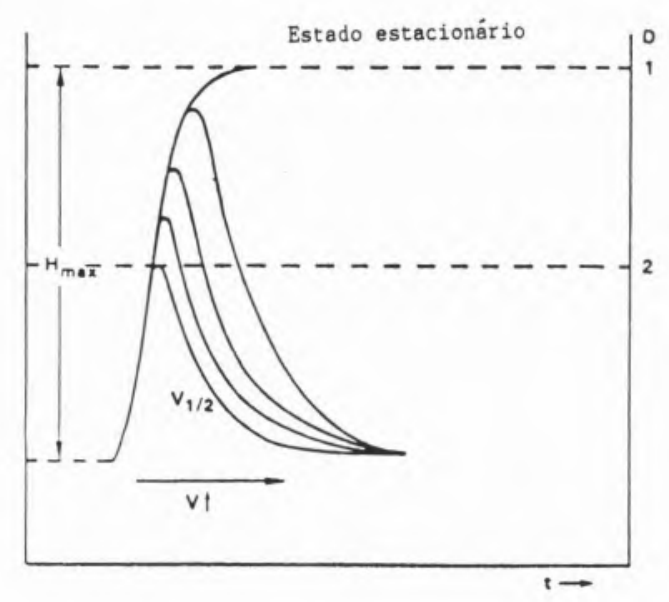

Figura 4 - Efeito da quantidade de amostra injectada, na altura do pico

$\mathrm{V}_{1 / 2}$ : volume injectado correspondente $\mathrm{a} \mathrm{D}=2$

A influência do volume $V_{s}$ de amostra injectada traduz-se por uma modificação do sinal do detector, tal como se indica na Figura 4. A altura dos picos aumenta com a quantidade injectada enquanto 0 coeficiente de diluição diminui; a altura do pico tende para um valor limite que corresponderia ao estado estacionário. A este nivel, a altura do pico corresponde ao sinal dado pela amostra não diluída e portanto a um coeficiente $\mathrm{D}$ unitário. Define-se $\mathrm{V}_{1 / 2}$ como 0 volume de amostra necessário para que 0 valor do sinal seja metade do que seria para 0 estado estacionário. Para volumes injectados inferiores a $V_{1 / 2}$ é geralmente válido admitir proporcionalidade entre 
volume injectado e altura de pico.

Altura de pico e tempo de permanência em função do fluxo e do comprimento e geometria do percurso

0 percurso do reactor entre a injecção e a detecção pode ter comprimentos, diâmetros e geometrias diferentes. Para um diâmetro interior, $\mathrm{d}$, constante, um comprimento $L$ e um fluxo $Q_{0}$ tempo médio, $t$, de permanência da zona ocupada pela amostra é dado pela relação

$$
t=\pi(d / 2)^{2} L / Q
$$

Sob um ponto de vista prático e para casos simples sendo possível relacionar 0 tempo médio de permanência e 0 coeficiente de dispersão [16] esta fórmula permite avaliar a priori os parâmetros de uma montagem FIA e fornece um meio de verificar 0 seu funcionamento.

\section{Dispersão e frequência de injecção}

A dispersão da amostra e a forma do sinal de FIA, particularmente a largura do pico, condicionam a frequência da análise permitida pela técnica. 0 tempo total, $\mathrm{t}_{\max }$, necessário para que 0 signal retome a linha de base é, admitindo a hipótese gaussiana [17]:

$$
t_{\max }=6 \sigma / Q
$$

onde $\sigma / \mathrm{ml}$ é o desvio padrão da curva, sinal vs. volume. Pode admitir-se que nas técnicas de injecção em fluxo, a variância global do sinal reflecte de forma aditiva as diferentes contribuições parcelares [18]

$$
\sigma_{\text {tot }}^{2}=\sigma_{\text {inj }}^{2}+\sigma_{\text {transp }}^{2}{ }^{+} \sigma_{\text {detec }}^{2}
$$

0 número máximo de injecções possiveis por hora, sem que haja sobreposição significativa de dois picos consecutivos é

$$
N=60 / t_{\max }
$$

Se 0 sinal se afasta da forma gaussiana, admite-se que a largura do pico, $\mathrm{t}_{\max }$, é igual a $\left(5 \mathrm{~S}_{1 / 2} / \mathrm{Q}\right)$ onde $\mathrm{S}_{1 / 2}$ representa 0 volume em $\mathrm{ml}$, escoado entre 0 princípio do pico e o seu máximo: calcula-se então 0 número máximo de análises com 0 auxilio da relação (8).

\section{Regras de utilização da dispersão}

0 valor do coeficiente de dispersão
D pode constituir um primeiro critério de classificação das técnicas de injecção em fluxo contínuo. Conforme as aplicações em vista, assim será desejável um valor ou menor de $D$, tendo no entanto em consideração que geralmente, quanto maior for esse valor, menor será a sensibilidade do método. Considera-se normalmente 0 seguinte critério classificativo:

- Diluição Limitada $(1<\mathrm{D}<3)$ : Seleccionada para 0 caso em que 0 único objectivo é o transporte da zona de amostra injectada até ao detector, preservando ao máximo a sua identidade;

- Diluição Média $(3<D<10)$ : Este caso é observado quando existe reacção química entre a amostra e reagentes do liquido transportador a fim de produzir ou consumir a expécie química que é detectada (caso das titulações); 0 aumento do tempo de residência e consequentemente o factor de dispersão permitem 0 desenrolar da reacção de forma a que sejam detectáveis variações de sinal correspondentes à mudança de concentração da espécie química em questão;

— Diluição Grande $(D>10)$ : Se a reacção química é lenta torna-se necessário aumentar o tempo de reacção, ou seja 0 tempo de residência, 0 que se consegue aumentando, por exemplo, o comprimento dos tubos.

Com base nas grandezas e relações definidas anteriormente podem enunciar-se algumas regras práticas de utilização em FIA:

- A dispersão depende do volume de amostra injectada; quando aumenta verifica-se uma amplificação do sinal que corresponde a uma maior sensibilidade do método.

- Obtém-se dispersão limitada para volumes injectados inferiores a $V_{1 / 2}$ e com tubagem o mais curta possível.

- A dispersão pode ser controlada por intermédio do fluxo transportador, $Q$, do diâmetro de do comprimento $\mathrm{L}$ do tubo até ao detector.

A inclusão de uma câmara de mistura num dispositivo de FIA, conduzirá a um aumento da dispersão e consequente diminuição da sensibilidade.

- A cadência da análise permitida depende da dispersão e é tanto maior quanto menores forem os volumes injectados.

\section{MEDIÇÃO EM FIA}

Se a técnica de medição clássica consiste em medir a altura (ou área) do pico decorrente de cada injecção de amostra, existem outras formas que a seguir se descrevem e que resultam da existência de um perfil de concentração da espécie detectada ao longo do tempo, ou seja de um gradiente.

\section{Gradiente:}

Verificando-se uma perfeita reprodutividade do fenómeno da dispersão, torna-se possivel utilizar o gradiente para medir o sinal a um dado tempo que não corresponda necessariamente ao máximo do pico, Figura 5.

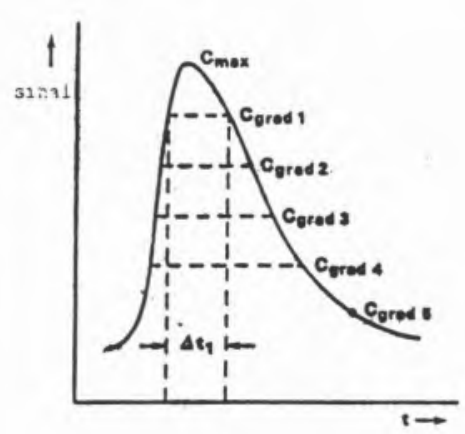

Figura 5 - Intervalo de tempo $\Delta$ t, entre dois sinais iguais correspondentes à mesma dispersão.

\section{Largura do pico:}

A largura do pico é igualmente um parâmetro de utilidade analítica; corresponde a um intervalo de tempo $\delta$ t medido para dois valores idênticos do sinal, tomados de um e de outro lado da curva, cuja equação tem a forma [19]

$$
\delta \mathrm{t}=\mathrm{k}_{1} \log \mathrm{C}+\mathrm{k}_{2}
$$

Dada a relação logarítmica, este parâmetro permite frequentemente extensão da aplicação do método a uma maior gama de concentrações da espécie doseada e encontra particular aplicação nas titulações.

\section{Titulações:}

No caso em que o transporte da amostra é acompanhado de reacção química de um dos seus elementos $A$ com um dos constituintes B do fluido transportador

$$
A+B \rightarrow C
$$

a curva resposta, seja qual destas for a 
espécie detectada, corresponde aos diferentes valores assumidos das concentrações $C_{A}$ e $C_{B}$ resultantes da dispersão da reacção química $\left(\mathrm{C}_{A} / \mathrm{C}_{B}>1\right.$ junto do pico; $C_{A} / C_{B}<1$ para maiores afastamentos ao pico). Existem portanto dois ponto $t_{1}$ e $t_{2}$ nesta curva tais que as concentrações $C_{A}$ e $C_{B}$ são iguais; estes dois pontos correspondem portanto, por definição, ao ponto de equivalência da reaç̧ão, correspondendo assim a um mesmo factor de diluição. A largura do pico é dada por uma relação análoga à relação (9)

$$
\delta \mathrm{t}=\mathrm{k}_{1} \log \left(\mathrm{C}_{\mathrm{A}} / \mathrm{C}_{\mathrm{B}}\right)+\mathrm{k}_{2}
$$

Para determinadas condições experimentais, existe portanto uma relação que permite determinar $C_{A}$ da espécie doseada pela reacção química. $A$ localização dos pontos $t_{1}$ e $t_{2}$ pode ser facilitada pela utilização de indicadores corados.

\section{INSTRUMENTAÇÃO}

Para pôr em prática 0 princípio mais simples da análise de injecção em fluxo, ou seja, a injecção de uma amostra num líquido transportador em movimento uniforme, que a conduz a um detector, o material de base necessário é constituido pelos seguintes elementos (Fig. 1) portador

- Reservatório de líquido trans-

- Meio de propulsão (bomba) do liquido transportator

$$
\begin{aligned}
& \text { - Injector } \\
& \text { - Reactor } \\
& \text { - Detector e registador }
\end{aligned}
$$

\section{Bomba}

Na análise em fluxo contínuo, que não exige pressões tão elevadas como a cromatografia liquida de alta pressão (HPLC) e requer fluxos compreendidos geralmente entre 1 e $4 \mathrm{ml} \cdot \mathrm{min}^{-1}$, utilizase frequentemente uma bomba peristáltica, cujas vantagens são bem conhecidas. São dispositivos com pequeno tempo de resposta e capazes de assegurar fluxos constantes, permitindo ainda 0 transporte simultâneo de vários líquidos, inclusivamente a velocidades diferentes que dependerão do diâmetro interno dos tubos. Há no entanto que ter em conta que, por construção, as bombas peristálticas apresentam pulsações e problemas de electricidade estática originada na friç̧ão dos rolamentos sobre os tubos, que podem afectar o sinal, particularmente se ele é fornecido por um detector potenciométrico.

\section{Injector e Modo de Injecção}

Comparada com outras técnicas de fluxo (cromatografia e fluxo segmentado) a análise em fluxo contínuo atribui à injecção da amostra no líquido transportador impotância fundamental. Esta operação deve conduzir à formação de uma zona de amostra perfeitamente definida e reprodutivel. Dela dependem o tempo de residência e sobretudo 0 desvio padrão da curva definida pelo sinal obtido à passagem no detector.

Em FIA distinguem-se dois grandes tipos de injecção conforme se controla o volume injectado ou o tempo de injecção.

No primeiro caso, a amostra é injectada directamente com uma seringa, ou de uma forma mais geral, através de uma válvula de injecção de volume constante e perfeitamente conhecido. No segundo caso, denominado de «injecção hidrodinâmica", a aspiração da amostra a uma dada velocidade, fornece o volume desejado de amostra, dependendo do tempo de aspiração.

Os equipamentos adequados a uma injecção de volume são válvulas de injecção de anéis ou de gavetas, cuja descrição pormenorizada se pode encontrar em manuais de cromatografia [20]. É um sistema de comutação da válvula que assegura a passagem da amostra ao anel e de seguida ao líquido transportador.

A injecção hidrodinâmica da amostra é efectuada numa conduta de volume perfeitamente definido e atravessada pela amostra e percorrida pelo líquido transformador. Este tipo de injecção implica 0 uso de duas bombas peristálticas e a bombagem alternada de amostra e de transportador.

Não tem sido assinalada diferença significativa entre o comportamento de um modo e outro.

\section{Reactor ("Manifold")}

Todos os componentes de um dispositivo de FIA estão unidos entre si por tubos $(0,2 \mathrm{~mm} \leq \mathrm{d} \leq 0,8 \mathrm{~mm})$ de Teflon, PVC, ou de outros materiais, que formam depois da zona de injecção um enrolamento $(10 \mathrm{~cm} \leq \mathrm{L} \leq 50 \mathrm{~cm})$. 0 papel deste conjunto onde a amostra injectada se dispersa no líquido transportador é também 0 de permitir 0 desenrolar de reacções químicas entre a amostra e o líquido transportador, necessárias para pôr em evidência um dos constituintes da amostra. Tal reactor, que assim se pode chamar, constitui um elemento fundamental em FIA e é vulgarmente designado na literatura por "Manifold" ou "Chemifold" Existem outras geometrias para estes reactores (ex.: câmaras de mistura) que modificam o fenómeno da dispersão, aumentando a dispersão radial, conduzindo portanto a um aumento do factor de diluição.

\section{Detector e Registador}

A escolha de um detector põe problemas clássicos de linearidade, reprodutividade, sensibilidade, selectividade. As características dos detectores usados em FIA são, em princípio, análogas às dos detectores de cromatografia em fase liquida e a sua descrição pode encontrarse em numerosos trabalhos dessa área [20]. Existe no entanto a diferença que, não havendo separação dos componentes, exige-se maior especificidade aos detectores. Temos assistido sistematicamente ao desenvolvimento de aplicações de técnicas espectrofotométricas e electroquímicas de detecção a sistemas FIA [21-43]. De forma mais pontual têm sido utilizados outros métodos de detecção, ex.: entalpimetria, radioquímica.

0 registador que permite obter 0 sinal analítico transmitido num processo de FIA pode ser um simples registador gráfico, mas cada vez mais substituído por um microcomputador e impressora com vantagens acrescidas de automatização na pilotagem do funcionamento da aparelhagem e de tratamento dos dados analíticos.

\section{Aparelhagem Comercial de FIA}

Se inicialmente predominavam as vantagens modulares de FIA, desenvolvidas e construídas localmente conforme a aplicação específica a que se destinavam, hoje em dia podem encontrar-se já conjuntos integrados de que se dá alguns exemplos na Tabela 2.

Tabela 2. Lista de fabricantes de aparelhagem de FIA

$\begin{array}{lc}\text { Marca } & \text { País } \\ \text { TECATOR } & \\ \text { CONTROL EQUIPMENT CORPORATION } & \text { Suécia } \\ \text { FIATRON SYSTEMS INS } & \text { EUA } \\ \text { HITACHI } & \text { EUA } \\ \text { LACHAT INSTRUMENTS } & \text { Japão } \\ & \text { EUA }\end{array}$




\section{a r tig os}

\section{BIBLIOGRAFIA}

1. J. Ruzicka e E.H. Hansen, Anal. Chim. Acta, 78 (1975) 145.

2. G. Nagy, Z. Feher e E. Pungor, Anal. Chim. Acta, 52 (1970) 47.

3. W.F. Van de Linden, T.R.A.C. 1 (1982) 188.

4. J. Ruzicka e E.H. Hansen, Flow Injection Analysis, 2." edição, J.Wiley, New York, 1988.

5. J. Ruzicka, E.H. Hansen e H. Mosbaek, Anal. Chim. Acta, 92 (1977) 235.

6. 0. Aström, Anal. Chim. Acta 105 (1979) 67.

7. A. Shaw, C. Karlson e J. Möller, An introduction to the use of Flow Injection Analysis, Tecator, 1988.

8. J. Ruzicka e E.H. Hansen, Anal. Chim Acta 106 (1979) 207.

9. M.Masoom e P.J. Worsfold, Anal. Chim. Acta 188 (1986) 281.

10. K.A. Holm, Anal. Chim. Acta 188 (1986) 285

11. Flow Injection Analysis Based on Enzymes or Antibodies. Ed. R.D. Smidd, VCH, New York, 1990.

12. A. Nabi e P.J. Worsfold, Anal. Proc. 23 (1986) 415

13. Y. Hayashi, K. Zaitsu e Y. Ohkura, Anal. Chim. Acta 186 (1986) 131

14. E.B. Milosavljevic, L. Solujic, J.H. Nelson e

J.L. Hendrix, Mikrochim. Acta 3 (1985) 353

15. Z. Fang, J.M. Harris, J. Ruzicka e E.H. Hansen, Anal. Chem. 57 (1985) 1457
16. A.U. Ramsing, J.Ruzicka e E.H. Hansen, Anal. Chim. Acta 129 (1981) 1.

17. J. Ruzicka e E.H. Hansen, Anal. Chim. Acta, 161 (1984) 1.

18. H. Poppe, Anal. Chim. Acta 114 (1980) 19

19. J.F. Tyson, Anal. Chim. Acta 179 (1986) 149.

20. R. Rosset, M. Caude e A. Jardy, Manuel pratique de chromatographie en phase liquide, Masson, Paris, 1982.

21. J. Ruzicka e J.W. B. Steart, Anal. Chim. Acta 79 (1975) 79.

22. J. Ruzicka, J.W.B. Steart e E.A.G. Zagatto, Anal. Chim. Acta 81 (1976) 387.

23. H. Bergamin, B. F. Reis, A.0. Jacinto e E.A.G. Zagatto, Anal. Chim. Acta 117 (1980) 81

24. J.W.B. Stewart, J. Ruzicka, H. Bergamin e E.A.G. Zagatto, Anal. Chim. Acta 81 (1976) 371.

25. Flow Injection Atomic Spectroscopy, ed. J.L. Burguera, M. Dekker, New York, 1989.

26. H. Morita, T. Kimoto e S. Shimomura, Anal. Lett. 16 (1983) 1187.

27. J.I. Braithwaite e J.N. Miller, Anal. Chim. Acta 106 (1979) 395

28. D.K. Morgan, N.D. Danielson e J.E. Katon, Anal. Lett. 18 (1985) 1979.

29. D.J. Curran e W.G. Collier, Anal. Chim. Acta 117 (1985) 239.

30. G. Ham, Anal. Proc 18 (1981) 69

31. A.N. Strohl e D.J. Curran, Anal. Chem $\mathbf{5 1}$ (1979) 1045
32. J.W. Dieker e W.E. Van der Linden, Anal. Chim. Acta 114 (1980) 267.

33. J.A. Lown, R. Koile e D.C. Johnson, Anal. Chim. Acta 116 (1980) 33.

34. P. Maitoza e D.C. Johnson, Anal. Chim. Acta 118 (1980) 233

35. M.E. Meyerhoff e Y.M. Fraticelli, Anal. Lett. 14 (1981) 415.

36. P.L. Meschi, D.C. Johnson e G.R. Luecke Anal. Chim. Acta 124 (1981) 303

37. B. Persoson e L. Rosén, Anal. Chim. Acta 123 (1981) 115.

38. H.B. Hanekamp, P. Bos e 0. Vittori, Anal. Chim. Acta 131 (1981) 149

39. J. Ruzicka, E.H. Hansen e E.A.G. Zagatto, Anal. Chim. Acta 88 (1977) 1.

40. E.H. Hansen, A.K. Ghose e J. Ruzicka, Analyst 102 (1977) 705.

41. E.H. Hansen, F.J. Krug, A.K. Ghose e J Ruzicka, Analyst 102 (1977) 714

42. W. Frenzel e P. Brâtter, Anal. Chim. Acta 188 (1986) 151.

43. J.M.C.S. Magalhães e A. Machado, Portugaliae Electrochim. Acta 9 (1991) 429

*Centro de Electroquímica e Cinética da Universidade de Lisboa - Dept. Química, Universidade de Lisboa R. Escola Politécnica, 58, 1294 Lisboa Codex

\section{PRODUZIR VÁCUO PROTEGENDO O MEIO AMBIENTE}
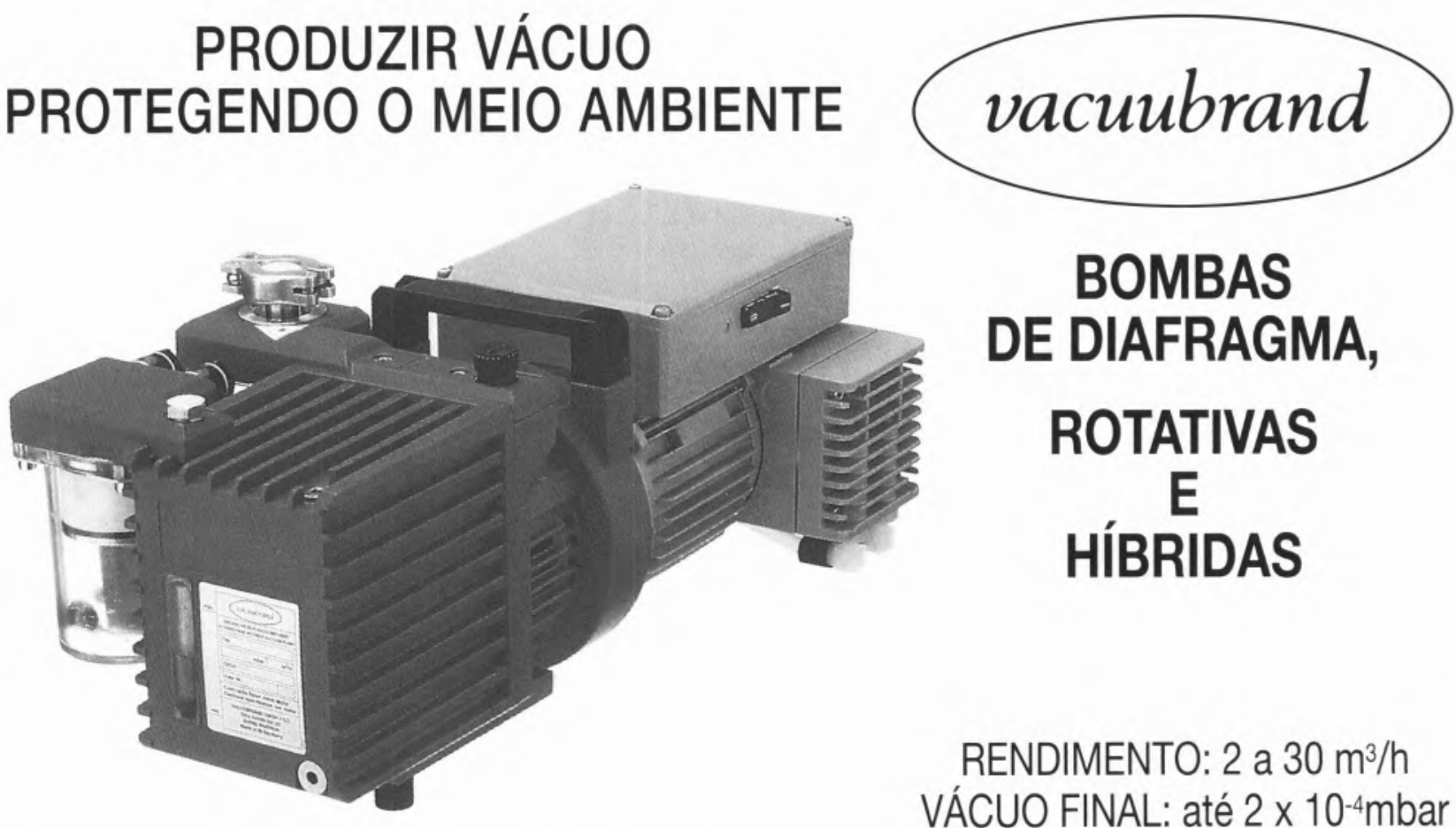

\section{BOMBAS DE DIAFRAGMA, ROTATIVAS}

E HÍBRIDAS

RENDIMENTO: 2 a $30 \mathrm{~m}^{3} / \mathrm{h}$ VÁCUO FINAL: até 2 × 10-4mbar

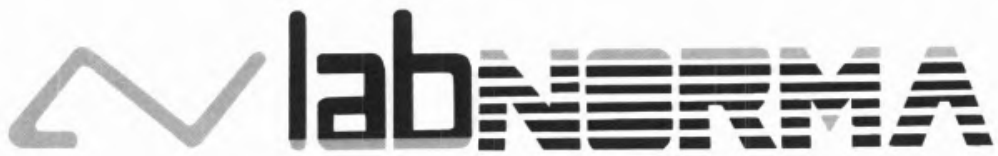

Equipamento de controlo de qualidade e investigação, Ida. 


\section{KONiKK \\ INSTRUMENTS}

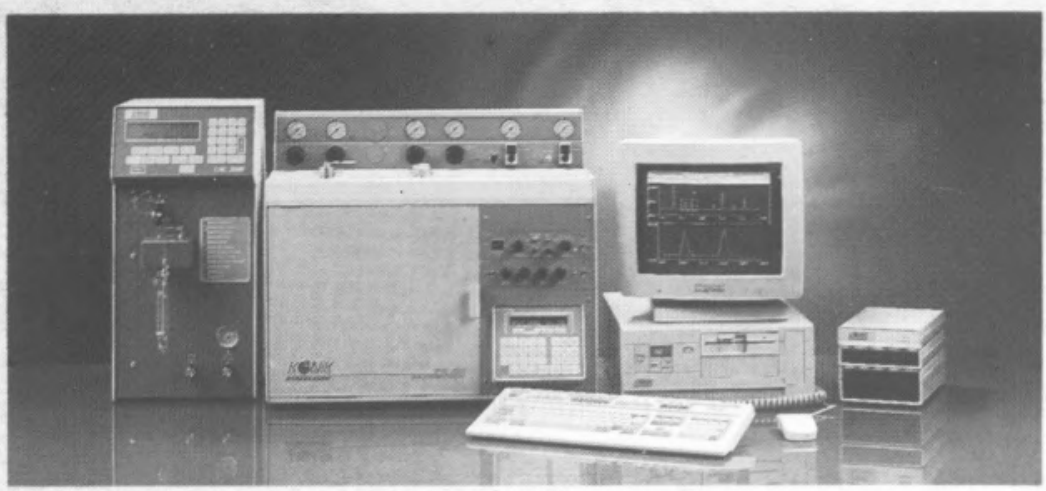

KONIK-HRGC - $3000 \mathrm{C}$ com eHead Spacen dinámico.

\section{- MODULARIDADE TOTAL}

Garantia de crescimento, modernização permanente

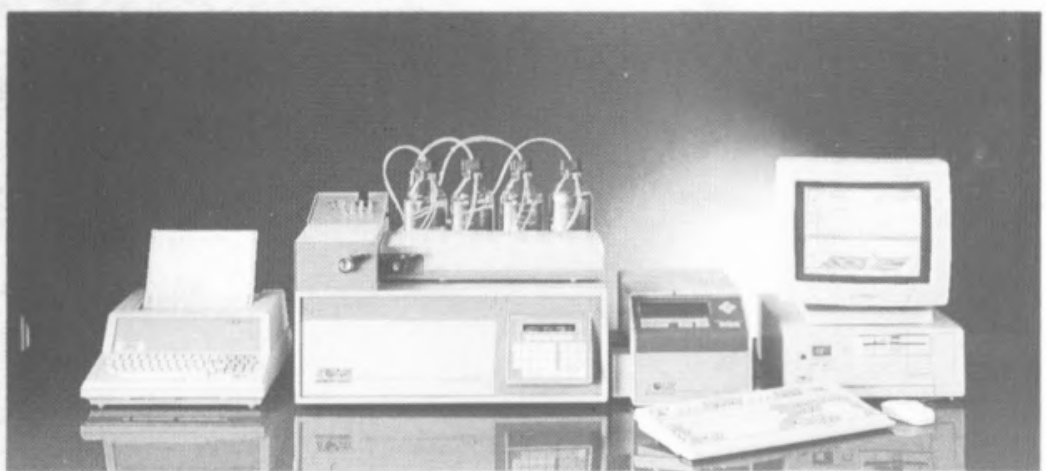

KONIK-HPLC - 500 B com detector de varrimentos espectrais.

\section{- VeRSATILIDADE}

Sistemas isocratico, de gradientes, semipreparativo biocompativel... uma contiguraçào adequada para cada necessidade analitica

\section{- automatizacão total}

Controle de modulos externos, comutaçáo de colunas, etc. atraves do microprocessado

\section{- REDUZida MANUTENĊÃO}

Garantia de elevado tempo util de funcionamento.

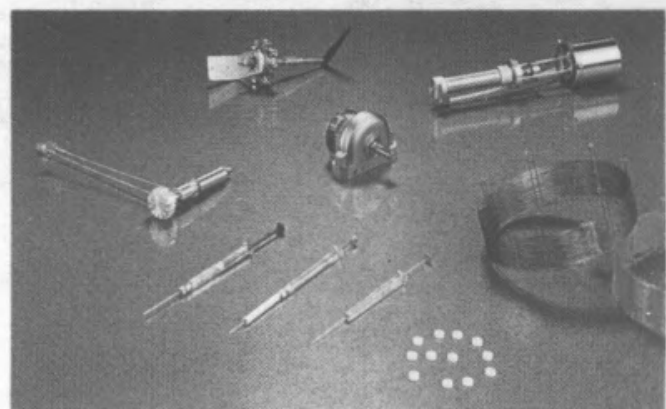

ACESSÓRIOS PARA CROMATOGRAFIA DE GASES

Colunas especiais:

- Gás natural e petróleo

- Meio ambiente (EPA)

- Gases permanentes

Seringas, filtros, septos, colunas

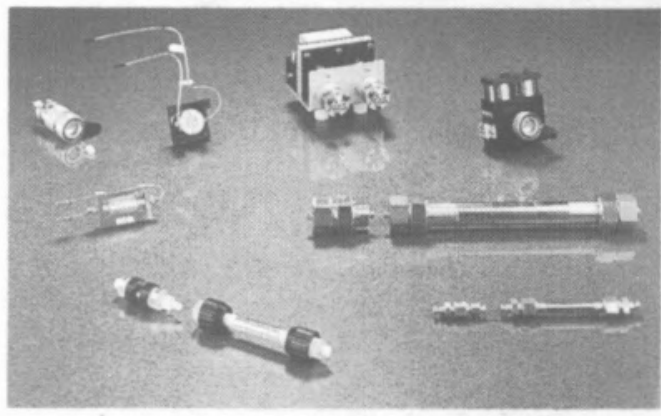

ACESSORIOS PARA CROMATOGRAFIA HPLC.

Colunas especiais

- Trigliceridos

- Drogas básicas

- Meio ambiente IEPA

- Quirais

Seringas, filtros, pré-colunas, colunas

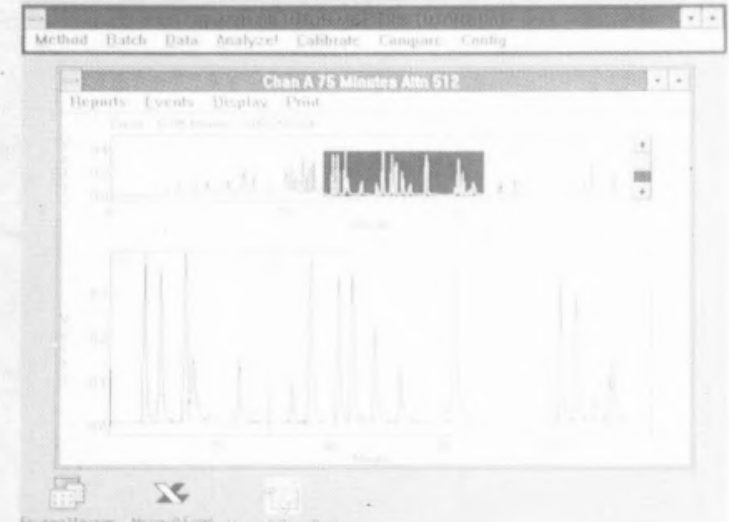

SOFTWARE DE INTEGRAÇÁO

com opção para "upgrade" de integradores.

- APOIO TÊCNICO E ANALITICO

Optimizaçào de métodos analiticos, treino e especializaçào

constante de utilizadores. Consultoria permanente

Laboratório de Aplicaçóes. Serviço técnico com treino

constante em tábrica

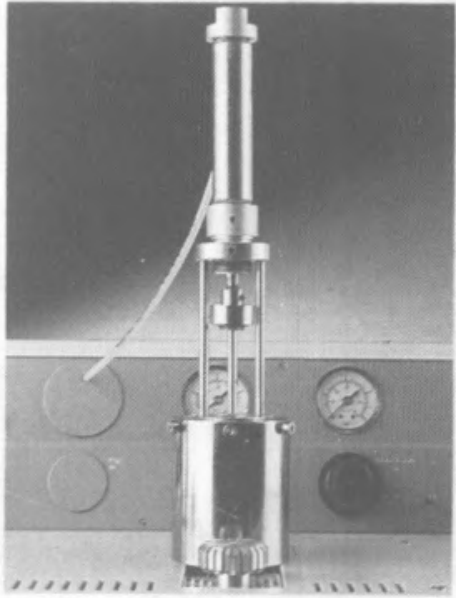

KONIK "HEAD SPACE" ESTATICO.

\section{- gama completa de} PERIFERICOS

Detectores. tratamento de dados. acessórios e consumiveis. 


\section{K NiK}

\section{INSTRUMENTSS.A.}

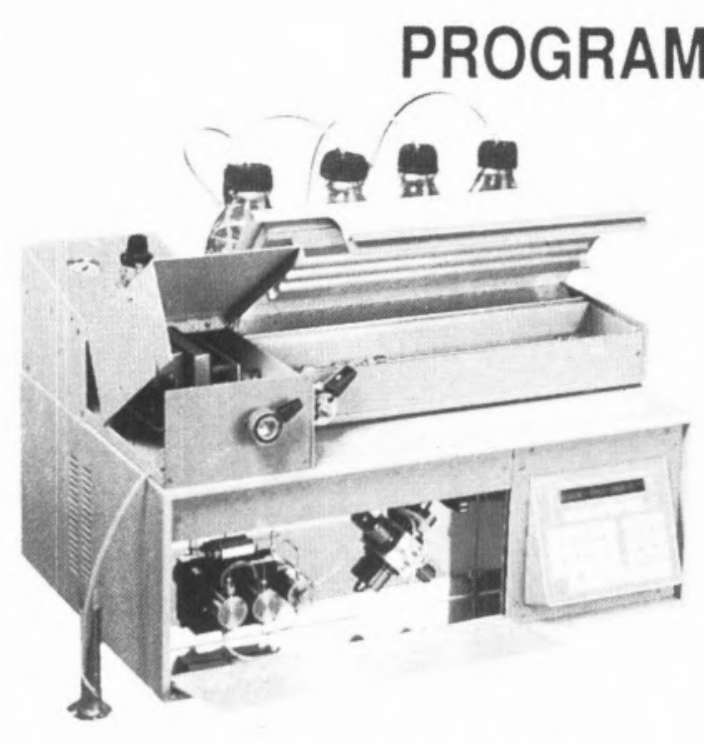

KONIK HPLC 500 B

- ElEVAdAS PRESTACOES

Bomba isenta de pulsacoes e reprocutibildace de "wx

- camara de autolavagem de pistoes

Proteccáo adicional contra a precip raça sal na ca tase mo.e.

- SISTEMA DE DESGASIFICACAO

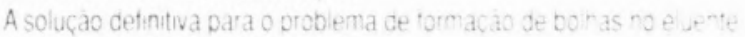

- FORNO NA VERSAO STANDARD

Modelos de gradientesi. Ootmzacao e reprocut d idace ce ara se

- GRADIENTES QUATERNARIOS

O sistema mas versatil. Doterte e eficaz dara tormacao de grac entes

- SISTEMA DE PURGA E AUTO-FERRAGEM DA BOMBA

Economia de tempo e solventes

- gama COMPLETA de SISTEMAS de INJECCAO

Standard microbore automatico biocompative

- CAPACIDADE DE PROGRAMACAO

Todos os parametros : tocos os metocos em memora nao vol a:

\section{NÃO SE CONFORME COM MENOS!!}

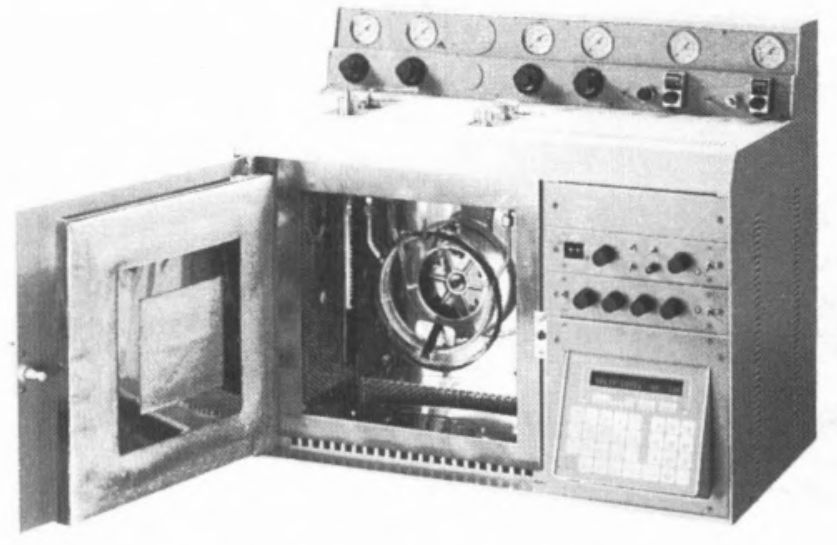

KONIK HRGC 3000 C

- configuracao bicanal

Con'cu mace e conto ne ncedencente para dois conjuntos

- FORNO DE ElEVAdAS PRESTACOES

Unna eva maxma estab ldade termica Elevada velocidade de

areecmento mo tempo entre ana ises

- programacao de temperatura

SISTEMAS DE INJECCAO

Opt m zacos dara as d stintas colunas e amostras capilar multimodo, on-column. convencional com loop de injeccáo etc

- CONTROLE DE PURGA DE SEPTO

in ector cas lar ce pressáo constante com purga de septo programada. Garantia de uma perte:a neccao

- gama completa de detectores

Geras. FID TCD Selectivos ECD. NPD FPD. HECD MSD

- programacao

Por me o de um disolay a 'anumerico. Armazenamento de metodos em memória almentada oor bater a

- PROTECCÁo

Programacáo de temperatura máx ma de coluna com autodesconexão automatica

\section{A MELHOR OPÇÃO EM GC!!}

\section{CENTROS KONIK DE FORMAÇÃO, SERVIÇO E VENDAS}

\section{EUROPA}

Konik Instruments, S.A. Rua Conde Redondo, 13-A-CV 1100 Lisboa (PORTUGAL)

Tel. (01) 575787

Fax (01) 575847
Konik Instruments, S.A. World Trade Center Porto

Av. da Boavista 1277/81 - Piso (-3)/CP3 4100 Porto (PORTUGAL) Tel. (02) 6068855 Fax (02) 6002135
Konik Instruments, S.A. Ctra. de Cerdanyola, 65-67 08190 Sant Cugat del Vallès Barcelona (ESPANHA) Tel. (93) 6743250 Fax (93) 6744150

\section{AMÉRICA}

Konik Instruments S.A.

Konik Sudamericana, S.A. 6065 N.W. 167th St. BLDG B-20 H. de la Quintana, 1450-1454 MIAMI-FLORIDA 33015 1602 FLORIDA Buenos Aires (EUA) (ARGENTINA)

Tel. (305) 557-2212

Fax (305) 556-4721
Tel. (1) 7910020 - 7978105

Fax (1) 7910262 